\title{
Political Economy Factors Shaping News Culture of Hyperlocal News Website www.ippodhu.com
}

\author{
Aquil Ahmad Khan \\ Department of Electronic Media and Mass Communication, Pondicherry University, Puducherry, India \\ Email: aquilkhan.khan@gmail.com
}

How to cite this paper: Khan, A.A. (2020) Political Economy Factors Shaping News Culture of Hyperlocal News Website www.ippodhu.com. Social Networking, 9, 39-51.

https://doi.org/10.4236/sn.2020.93003

Received: June 27, 2020

Accepted: July 27, 2020

Published: July 30, 2020

Copyright (อ 2020 by author(s) and Scientific Research Publishing Inc. This work is licensed under the Creative Commons Attribution International License (CC BY 4.0).

http://creativecommons.org/licenses/by/4.0/

\section{(c) (i) Open Access}

\begin{abstract}
In contemporary media ecosystem, media content is not only produced by employees rather it is also produced by its users in the form of curating stories, writing feedback, engaging in online discussions and at the same time disseminating the content through their personal online profiles. Keeping these views in mind, this paper critically examines the political economy of Ippodhu (Tamil Nadu based news website), a hyperlocal news application, in terms of digital labour, audience as participatory commodities and audience as producers, which Alvin Toffler terms as prosumer. Further, this paper explores how social media, analytics, or other analytical tools create value or anti-value for Ippodhu. The qualitative data obtained through in-depth interview reveals that readers/audiences of Ippodhu are commodified in two ways, first they consume the content of the website by spending their time, which will be sold to the advertisers and secondly by creating free content either in the writing stories, uploading photographs or even in the form of comment which will be consumed by other readers/audiences which result in the chain of production of values.
\end{abstract}

\section{Keywords}

Political Economy, Hyperlocal News Website, Use Value, Exchange Value, Prosumer, Audience Commodity, Immaterial Labour

\section{Introduction}

As traditional media are struggling hard to sustain in the cutting age of evolving technology and economic commotion, media producers are discovering new ways to identify, collect, and disseminate information. In recent times, the de- 
velopment of hyperlocal news websites is attracting the attention of most countries. Cohen argues that current debates about the future of digital journalism focus more on economic and technological aspects. There is an urgent need to discuss production practices and their effect on work and labour, because the commodification of labour and commodification of journalism are interlinked [1].

There have been several attempts by scholars study on few aspects of hyperlocal news media. Paulussen and D'heer [2] conducted a study to understand how hyperlocal newspapers are employing user-generated content to cover the hyperlocal news. While Shih, Han and Carroll [3] conducted a research to find out how hyperlocal news is relevant and has potential to empower community residents. Few recent studies on hyperlocal news focus on how public approach to professional norms of journalism and their funding [4] [5]. (Leckner, Tenor and Nygren, 2019; Tenor, 2018). Nielsen [6] conducted another study to understand how people perceive the journalism of hyperlocal.

Present hyperlocal scenario in India, with small infrastructure and limited resources, cannot be seen as an alternative to mainstream media, but play an important role in contributing to media plurality. Hyperlocal refers to online news or content pertaining to a village, town or city but still no agreed-upon unified definition. Ippodhu is an Independent news website having similar characteristics to Hyperlocal in many ways. The concept of hyperlocal is still a capacious term in India though place-based websites evoke characteristics of the local-specific media. Emerging digital-first media organisations are changing the production, distribution and consumption process of journalism which creates challenges to the autonomy of journalists and their collective power [7]. The production and consumption logic of hyperlocal news sites is hinged more on users and readers than only journalists. Idealists argue that the rise of digital media has expanded the scope for citizens of accessing content despite of availability of content such as blogging and citizen journalism have, despite of shrinkage newsrooms.

Changes in the production process of media are not merely because of technological advancement rather it is used as strategies to cut down the labour costs [8]. The twenty-first century has witnessed the rise of India as a major media producer and consumer market increasingly engaged with the global economy. This has led to different small players into the field of news media. In terms of news websites, all produced stories have use value as well as exchange value, and it is commodifiable. On a news website readers/audience is commodified in two ways, first they consume the content of a website by spending the time, which will be sold to the advertisers and secondly by creating free content (Immaterial labour) for the websites which will be consumed by other readers/audience.

Despite increasing popularization of hyperlocal news websites across the globe no serious attempt has been made by scholars to study the different problems associated with these organizations and especially the labour aspect. Hence, to go against the dominant narratives, the present study focuses on how au- 
dience/readers are exploited in Ippodhu in different ways. This paper tries to understand why a hyperlocal organisation like Ippodhu encourages audiences to produce content in the name of promoting participatory culture and does this practice creates value or anti-value for Ippodhu.

\section{Review of Literature}

\subsection{Hyperlocal Journalism and Its Development}

The concept of hyperlocal media is fixed and it is evolving on a continuum. Though the word "hyperlocal" appears in different research, academia, media industry as potential alternative tools for the future of news industry, but there is no agreed-upon definition. When there is no fixed definition of hyperlocal, almost any website can claim to be hyperlocal [9]. After going through different studies and listing down their definitions of hyperlocal they concluded that features of the definition should be intrinsic in the term "hyperlocal" and one needs to move beyond the general assumption of limiting it to the geographical limitations. They quoted one article which stresses that, journalism will die if it does not become more local, or even something called "hyperlocal" [10]. Another study says that content of such websites should give importance to community niches that should have hyperlocal news [11].

While there is no dearth of news due to contributions made by citizens to the production of news, hyperlocal journalism as an alternative to mainstream digital journalism has struggled, since its inception, to demonstrate its viability as a profitable business model. But citizen driven news has attracted a lot of audience on the digital space [12]. This article also talks about the report produced by Cardiff University which reports that hyperlocal websites in UK are struggling more than US based hyperlocal websites. The problems faced by UK based websites are not only of financial sustenance but also to do with the issue of discoverability, sustainability and recognition by conventional media and regulators.

Another study has been done to check the possibility of hyperlocal news outlets specially focusing on such websites which are owned and controlled independently. It was found that these websites give more coverage to civic discourses in order to create good image among readers. Jeffres, Atkins and Neuendrof [13] has done one study on localized newspaper and community politics and found that people are mostly inclined towards local problems and they prefer localised news websites. A survey based study in United States found that people with little education use more social media than highly educated people [14]. Other study in UK reported that high coverage to public-interest stories in the form of investigations are given by community news producers [15].

\subsection{Journalism Practices through Labour Perspective}

The concept of prosumer was developed by Alvin Toffler during early 1980s. The basic concept of prosumer is, it blurs the line through which we can separates producer from consumer [16]. The concept of prosumer differs from me- 
dium to medium. In the broadcast medium audiences produce meanings of programs, whereas on digital media prosumers not just produce meanings of programs, but also generate content with users and build social relations. Christian Fuch argues that though Toffler considers prosumption as arrival of new form of economic and political democracy, labour autonomy and autonomous self-production but he overlooks the other side of prosumption which is used for outsourcing work to user/consumer, who work without pay [17]. In this model organization reduces the investment cost, especially in the labour section and exploits the labour who works for free.

According to Tiziana Terranova [18] unwaged immaterial labourers do almost similar work as waged immaterial labourers and they also needs the similar amount of effort from body and mind for producing content, and this work may catch hold of massive profits for those who own the platform or website. Apart from Terranova, other authors like Maurizio Lazzarato, Michael Hardt, and Antonio Negri have drawn motivation from Michel Foucault and argued that immaterial labour is biopolitical as it purchases control and affective capacities of immaterial workers. These authors also argue that waged immaterial labour reshapes the subjectivities of workers by reorienting their affective capacities [19].

In capitalism labour process is implied for the appropriation and expansion of surplus value: labour is motivated to create something which can help in expanding capital [8]. Brown in his thesis explains that free or unwaged immaterial labour must be considered "work" as it is not only temporally, affectively, and physically taxing, but it also generates huge amount of money for those who own the means of production which helps in accumulating good profit [19]. The concept of immaterial labour very much accepted and appreciated among media companies. Digital-first media companies are escalating the exploitation process by promoting the use of free contents from workers and from readers, this model has been highly appropriated by Huffington Post [20].

The use values relates to the utility of the physical properties of a product, which realized only upon its use. While exchange value is the price of a particular good, which can be bought and sold in the market. The concept of use-value and exchange value drives the whole process of production and circulation. Use values are mainly dealing with its use or consumption while exchange-values are only realized in sale and purchase. This paper propose three research questions which implies the audience as commodity by Dallas Smythe and concept of prosumer by Alvin Toffler as well as Marx concept of Use values and Exchange values to understand the labour process involved in Ippodhu.

\section{Research Questions}

RQ 1: What kind of digital labour involved in Ippodhu, in terms of, audience as participatory commodities and audience as producers?

RQ 2: What is use the values and exchange values of Ippodhu's content and how its readers/viewers are commodified? 


\section{Method}

This study has adopted qualitative research method. For this study researcher has conducted in-depth interview with editor of Ippodhu and other three employees. These employees include Production manager, Chief visualizer and Advertising head. Interviews were conducted in English language and recorded with their prior permission. The interview of editor was conducted in Chennai at Ippodhu office while interviews of other employees were conducted over phone. The entire interviews were transcribed and analyzed thematically.

\section{Analysis}

Analysis of qualitative data obtained, interview transcript has been presented in following broader themes.

RQ 1: What kind of digital labour involved in Ippodhu, in terms of, audience as participatory commodities and audience as producers?

This websites is functional with a very small team of seven persons which includes two people working exclusively for advertisement and one person is working at Madurai bureau. This website provides contents on different platforms like mobile app, Facebook page, YouTube channel, Twitter account and on its own website. Readers of this news website are encouraged to generate news stories or share photographs or videos. This is more prevalent in the mobile application of Ippodhu. The editor of this website is very deterministic in their approach and instead of accepting the free labour from audience they are manifesting themselves as space provider for democratic media. He says that:

We are technology accessible to people even villages which has only $2 \mathrm{G}$ connections they can make use of that. It is light and designed for people. We believe that now people are the news givers, people are the journalists so, they should be empowered to tell the stories so, we are designed in that way.

This websites also provides half an hour discussions through Facebook live on daily basis and later this programmes are put on the official websites of ippodhu.com. In these programmes expert from different people are invited to talk part in the discussion and they are not paid. But the management of this website use the data of traffic created by this programme and attracts the advertisers which in genuinely doesn't cost much investment. The editor says that:

No, we don't have the capacity to pay them now, so they are motivated by the fact that we are doing independent journalism and they like the way we are doing things so, they are coming out of their public interests.

The content produce by readers is not only in the form of stories, video or opinion pieces rather it can be in the form of comments, feedbacks, shares, likes anything. These things are produced by readers by spending some time which is helping the website in generating traffic and these comments may become the content or issue of discussions for other readers. In both ways website is having 
upper hand to make money out of their free or unconscious labour. The contents of this website contributed by readers are not brings into the notice of staffs rather editor himself take the decision whether it has to go on the website or not. The production manager of this site says that:

No, that is not happening for me. May be you have ask this to the editor. I never got like that.

RQ 2: What is use the values and exchange values of Ippodhu's content and how its readers/viewers are commodified?

As it's already explained in theoretical underpinnings that use values relates to the utility of the physical properties of a product, which is realized only upon its use. While exchange value is the price of a particular good, which can be bought and sold in the market. Keeping these meanings in the mind if we try to understand the Use value and Exchange value of ippodhu.com contents, then we can argue that the information, facts or news this website gives can be considered as use values of its. But in terms of exchange value will have multifaceted understanding. Here the basic exchange value can be seen in the form of attracting advertisements, increasing readership or viewership and getting several donations from public or from others.

The main question that arises from this understanding is to know how increasing exchange values are affecting the use values of the content or is the use value of any news determined by its exchange values. If it's the case then producers must be exaggerating news or produce news the way channels are doing to get TRPs to increase the exchange value which Baudrillard termed as 'Hyperreality'. According to him the boundary between reality and representation blurs. The editor explains that when he approaches the advertiser he gives some data and figures so, that they can take decision accordingly:

Google analytics is our numbers, when we go to advertisers, we give the number from Google analytics though we have not grown up to that extent.

\subsection{Labour 2.0 and Exploitation}

Labour exploitation is very much invisible in the digital age. Many a time neither exploiter and nor the exploited is able to recognise the exploitative process. Different scholars have different terms depending its nature and situations. Terrenova has termed it free labour, another scholar says it as immaterial and the very recent one where some people are naming it as voluntary labour. On the digital platform these are mainly dealing with audience participation but if we minutely observe then it's prevalent for the working employees also. Quite often they voluntarily do extra time duty, not availing proper leave, working from home also during their leisure time or sharing website's content on their personal timeline etc. Many times they are not aware of how their labour helps organization to gain extra values which Marx says as surplus value. The production manager very happily utters that: 
Yes he (editor) allowed us to take leave but I don't take leave much and if some is absent then other has to care of his/her work

It's a kind of emotional labour, where employees of organization highly imbibe a new kind of professionalism in their personal life which is intruded by work. Detaching from their work appears a big loss to them and this loyal attitude of employees helps in commodifying their labour to accumulate surplus value. The chief visualizer says that:

If I have time I will do that from house otherwise we have to find some alternative things. So somehow I have to manage not necessarily but I have to.

These employees of ippodhu.com always take their work as own work and it's very much related to their symbolic value. Even if there health is bad they perform their task from their home. On the part organization or management they consider these employees as mere an employee who will be paid fixed salary they cannot become the part surplus values which was gain on their hardship and sacrifice. While explaining her working routines she empathetically says that "sometimes if I feel like headache and all then sit at home and work".

\subsection{Immaterial Labour in the Name of Newsroom Culture}

As previous theme discusses about volunteer labour which is chosen by the employees themselves but there are some works which they are asked to do in the name of newsroom culture that too free. These works may have different forms varying from one organization to another organization but in the case ippodhu.com the researcher could identify two forms of immaterial labour through interviews. In the first one employees/journalists have to share all important stories on their personal Facebook or twitter account and second one and the more tedious one they have to actively participate in the discussion with audience which may happen anytime. These are not just the choice journalists have but guidelines given to them, one of the female journalists says that:

Yes, I share it on my Facebook timeline because my editor has asked to do it.

Ya absolutely, we have to... there is a culture here. We have some sort of instructions from the editor so we have to do that, who so ever work here have to share and post, that's how we can grow. We have to share otherwise we can't get viewer you know? So we have to share everything.

On the other side almost all the news websites have their Facebook page where they share all big stories. Facebook provides in built bots which are modifiable according to page holder's compatibility. The number of likes and shares on Facebook definitely help them to set priorities. Alexa ranking help websites to project their status to advertisers to attract advertising. One important thing which is helping this website in getting traffic is Google news trending and Search Engine Optimization. They look at trending issues and then decide their 
content accordingly. The production manager says that:

Actually, it should be trending subjects/topic. I have to check Google trending, twitter trending then write accordingly. We do a lot of SEO and other services also.

The importance of algorithm can't be ignored in the current scenario of digital journalism. People who don't have prior experience in the field of journalism are going through tough situation. They are seriously asked to learn the mechanism of algorithm. These things are even becoming important in small news website like ippodhu.com. The Chief visualizer of this website says that "Basically I don't understand the algorithms of internet system. Slowly I am learning".

\subsection{Evolving Business Model}

Digital journalism has not found the fixed business model till now and it's always in the process of identifying best suited model. Currently Indian news websites are generally following three kinds of business models: AdSense, Reader's subscription and crowd sourcing. Different news websites are experimenting their own model depending on their own political economic situation. As this paper earlier discussed in the introduction part that concept of hyperlocal news website is not popular in India so, obviously here we don't have proper defined business model. Though Ippodhu is a very small website in terms of infrastructure and readership, it has come up with some innovative business models which are quite effective for a hyperlocal news website. The editor says "I don't think finding the business model will be an issue, if you have the will to lead independent journalism in the state of Tamil Nadu you will evolve your business model. On the fly we are doing that, By God's grace we are doing that".

Ippodhu has come up with three kinds of business models. First one is micro donation, asking readers to pay for what they read. Second one is native advertising, which is catching across the globe. In this model advertisements are given in the form news with a disclaimer that it is a promotional activity. Third one is display/banner advertising which is quite normal in other websites also, where advertisement of any product or service is put on the website. Editor explains the business model of Ippodhu as:

In digital ecosystems, I think we'll have to have multiple revenue streams including micro donation asking readers to pay for what they read. After reading your $10-12$ articles nicely telling them, look we are building an ecosystem and to sustain this ecosystem, please support us. Another thing is native advertising. It is basically content which is differentiated from the editorial content with a disclaimer that this is a promotional activity. We have also other set that is display advertising the banner advertising.

Though Ippodhu is covering and providing the news to entire Tamil Nadu but its focus area to attract advertisers only in Chennai. They are mainly focusing on small scale industries because they have good respects for Tamil media. The ad- 
vertising head says that:

I am meeting different kind of people, right now only in Chennai. I have more than one lakh database mainly of Small scale businesses. Actually, In Tamil Nadu small scale businesses give respects to the media.

Unlike other news websites, Ippodhu is not working with Google for advertisement though it takes the technological supports from Google. Editor says that:

We don't work with Google, from the beginning we don't want to work with Google, some people may love to do this but we don't and it's a conscious decision. We are working with Google on technology but for advertising we have our people and strategy.

\section{Discussion}

This study brings out different factors which determine the political economy of Ippodhu. Through the analysis it came into the picture that the readers of this news website are producing the content in different forms. Through the lens of Christian Fuch [21] concept of immaterial labour, it appears that readers are not simply consuming the news rather they are working free for this website. Taking this argument further if we bring the Dallas Smythe [22] concept of "audience as commodity" it gives different angles to the reality. Here audience are not simply consuming the content or creating the content rather they are working in terms of generating traffic for the website which will be sold to the advertisers. In this way this website is able to generate the chain of production of values. In both ways website is having upper hand to make money out of their free or unconscious labour.

Murdock [23] explained that cultural and communication products have threefold relationship with commodity culture. Firstly because readers have to spend some money for accessing the content/product of the media, secondly media provides platform to companies for advertising their commodities that is why they back the consumption of commodities and consumer culture. And third, communication enhances a commodity culture because it celebrates consumption and the people who present consumption. If we try to fix this argument with the functioning of Ippodhu then we can visualize almost similar picture. The users of Ippodhu must be paying some amount for internet service to access the content of this site and off course the management of Ippodhu provides space to the companies for advertising their product which means they are supporting consumption of commodities and consumer culture. And editor is feeling proud and claiming their increasing visitors which is nothing but merely celebrating commodity culture and people who are consuming it. But Jackson [24] debates that, news is not simply a commodity like other commodity because it is a contested commodity and has dual role. News is expected to be serving the public interest at the same time pursuing profit for the corporate owners. 
After investigating the Use value and Exchange value aspects of Ippodhu contents, researcher has found that the information, facts or news produced by this website has some use values. But it hardly matters for the websites until or unless it is able to produce exchange values in the form of attracting advertisements, increasing readership/viewership and getting several donations from public or from others. As Braverman [8] has discussed that in capitalist labour process, production does not only takes place for use values but also for value. And this value is not only in terms of exchange values rather surplus value also. The argument of Marx which says people who have money or control over the means of production will have control over the mental production. It means if someone has money, can run the websites and produce the content. In the case of hyperlocal, does it work other way, means someone publishes the content to get the money. Can these orders be seen as superstructure, base, superstructure, base instead of base, superstructure and base?

Work is exploited even when someone is unwell because following the introduction of technologies specially web 2.0 technologies, the labour process have changed. One of the root causes is cutting down on the number of employees leads to spending less. On the other hand there is no compromise on surplus value for which other employees have to do more work. In the case of labour exploitation in the digital age people are ignorant on both sides. Many a times neither exploiter and nor exploited person is able to recognise the exploitation aspects. In this study we found that it's happening for both audience and working employees as well. Quite often they voluntarily do extra time duty, not availing proper leave, even working from home during their leisure time or sharing website's content on their personal timeline etc. Many times they are not aware of fact that ultimately their effort will help the particular organization to add extra values which Marx says as surplus value.

One of the offshoots of digital interventions in journalism seems to be that of cutting down on the number of employees. On the other hand there is no compromise on surplus value for which other employees have to do more work. Labour produces not only commodities rather it produces social and capital relationship. In the era of convergence, everyone is involved in the production of information. Content of the commodity explains the change in labour process using technologies, work style (full time/part time), long hours and relaxing work norms. Immaterial labour 2.0 further blurs the existing fuzzy distinction between work time and leisure time [25].

The main question arises from this understanding is like how increasing exchange values are affecting the use values of the content. Or does the use values of any news are determined by exchange values of it. If it's the case then producers are must be exaggerating the news to increase the exchange values which Baudrillard termed as Hyperreality. In the field of media news is not the end product but it creates new taste, image among readers. Labour produces not only commodities rather it produces social and capital relationship. In the era of convergence, everyone is involved in the production of information. Content of 
the commodity explains the change in labour process using technologies, work style (full time/part time), long hours, relaxing the work norms.

\section{Conclusions}

This study concludes that users of Ippodhu are gradually involved in the logic of capitalist operation and faces exploitation at two levels: one is to exploit the content value produced by the users and second is the value generated by the user browsing the advertisement. The incursion of technologies into journalistic practices has redefined what counts as socially necessary labour with multiskilling and efficacy in handling technologies becoming the foundational prerequisites. This has engendered an accumulated intensity of human labour that intermeshes with technological capabilities to produce stories instantly and distribute them on websites and social media platforms. This is much more than what is socially necessary and creates a spectacle that culminates in the extended labour time and tasks.

The sunny side of a digital journalist in Ippodhu might point to his/her sleight-of-hand expertise in managing a combination of tasks including the affective publics and communities that journalists produce in the process. These opportunities in no uncertain terms constitute the elements of a "well-designed spectacle" where societal issues and the labour involved are either erased, alienated or hidden. The resultant digital labour of news production, therefore, is in alignment with ideological presuppositions to monetise stories through its content and advertising targeted at audiences who read specific contents. Despite having different challenges to start and run hyperlocal website without organizational backing, Ippodhu is performing well and its management is very much hopeful about the future.

\section{Conflicts of Interest}

The author declares no conflicts of interest regarding the publication of this paper.

\section{References}

[1] Cohen, N.S. (2015) From Pink Slips to Pink Slime: Transforming Media Labor in Digital Age. The Communication Review, 18, 98-122. https://doi.org/10.1080/10714421.2015.1031996

[2] Leckner, S., Tenor, C. and Nygren, G. (2019) What about the Hyperlocals? The Drivers, Organisation and Economy of Independent News Media in Sweden. Journalism Practice, 13, 68-89. https://doi.org/10.1080/17512786.2017.1392254

[3] Nielsen, R.K. (2016) Folk Theories of Journalism. Journalism Studies, 17, 840-848. https://doi.org/10.1080/1461670X.2016.1165140

[4] Tenor, C. (2018) Hyperlocal News and Media Accountability Hyperlocal News and Media. Digital Journalism, 6, 1064-1077.

https://doi.org/10.1080/21670811.2018.1503059

[5] Paulussen, S. and D’heer, E. (2013) Using Citizens for Community Journalism: 
Findings from a Hyperlocal Media Project. Journalism Practice, 7, 588-603. https://doi.org/10.1080/17512786.2012.756667

[6] Shih, P.C., Han, K. and Carroll, J.M. (2014) Community Incident Chatter: Informing Local Incidents by Aggregating Local News and Social Media Content. Proceedings of the 11th International Conference on Information Systems for Crisis Response and Management, State College, May 2014, 772-776.

[7] Willnat, L. and Weaver, D.H. (2014) The American Journalist in the Digital Age: Key Findings. School of Journalism, Indiana University, Bloomington.

[8] Braverman, H. (1974) Labor and Monopoly Capital: The Degradation of Work in the Twentieth Century. Vol. 26, Monthly Review Press, New York.

https://doi.org/10.14452/MR-026-03-1974-07_1

[9] Metzgar, E.T., Kurpius, D.D. and Rowley, K.M. (1999) Defining Hyperlocal Media: Proposing a Framework for Discussion. New Media \& Society, 13, 772-787. https://doi.org/10.1177/1461444810385095

[10] Bunch, W. (2007) Forgetting Why Reporters Choose the Work They Do. Nieman Reports, Winter.

http://www.nieman.harvard.edu/reportsitem.aspx?id=100116

[11] American Press Institute (2009) Paid Content: Newspaper Economic Action Plan. http://www.niemanlab.org/pdfs/apireportmay09.pdf

[12] Wise, S. (2015) Hyperlocal Content at a Crossroad. FIPP, France.

[13] Jeffres, L.W., Atkin, D. and Neuendorf, K.A. (2002) A Model Linking Community Activity and Communication with Political Attitudes and Involvement in Neighborhoods. Political Communication, 19, 387-421. https://doi.org/10.1080/01957470290055574

[14] Bobkowski, P.S., Jiang, L.F., Peterlin, L.J. and Rodriguez, N.J. (2018) Who Gets Vocal about Hyperlocal. Journalism Practice, 13, 159-177. https://doi.org/10.1080/17512786.2017.1419827

[15] Williams, A., Harte, D. and Turner, J. (2015) The Value of UK Hyperlocal Community News. Digital Journalism, 3, 680-703. https://doi.org/10.1080/21670811.2014.965932

[16] Toffler, A. (1980) The Third Wave. Bantam Books, New York.

[17] Fuchs, C. (2012) Google Capitalism. Triple C-Cognition, Communication, Cooperation, 10, 42-48. https://doi.org/10.31269/triplec.v10i1.304

[18] Terranova, T. (2000) Free Labor: Producing Culture for the Digital Economy. Social Text, 18, 33-58. https://doi.org/10.1215/01642472-18-2_63-33

[19] Brown, B.A. (2012) Will Work for Free: Examining the Biopolitics of Unwaged Immaterial Labour. https://ir.lib.uwo.ca/etd/620

[20] McChesney, R.W. (2013) Digital Disconnect: How Capitalism Is Turning the Internet against Democracy. New Press, New York.

[21] Fuch, C. (2010) The Political Economy of Privacy on Facebook. Television \& news media, 13, 139-159. https://doi.org/10.1177/1527476411415699

[22] Smythe, D.W. (1981) On the Audience Commodity and Its Work. In: Gigi Durham, M. and Kellner, D.M., Eds., Media and Cultural Studies: Keyworks, Blackwell Publishing, Hong Kong, 230-256.

[23] Murdock, G. (2011) Commodities, Gifts and Public Goods. In: Wasko, J., Murdock, G. and Sousa, H., Eds., The Handbook of Political Economy of Communication, Blackwell Publishing, West Sussex, 13-40. 
[24] Jackson, P.T. (2009) News as a Contested Commodity: A Clash of Capitalist and Journalistic Imperatives. Journal of Mass Media Ethics, 24, 146-163. https://doi.org/10.1080/08900520902905349

[25] Lazzarato, M. (1996) Immaterial Labour. In: Hardt, M. and Virno, P., Eds., Radical Thought in Italy. A Potential Politics, University of Minnesota Press, Minneapolis and London, 133-147. 